\title{
La población en la mitad: Reflexiones sobre Bojayá y La Sierra*
}

\author{
Juan David Mesa** \\ (judamesa69@hotmail.com)
}

Articulo de reflexión recibido el 04/18/2014 y aprobado el 27/01/2015.

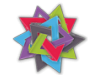

Cómo citar este artículo:

MESA, Juan David (2015). "La población en la mitad: Reflexiones sobre Bojayá y La Sierra”. En: Trans-pasando Fronteras, Núm. 8, pp. 125-143. Cali, Colombia: Centro de Estudios Interdisciplinarios, Jurídicos, Sociales y Humanistas (CIES), Facultad de Derecho y Ciencias Sociales, Universidad Icesi.

DOI: $10.18046 /$ retf.i8.2234
\end{abstract}

\begin{abstract}
Resumen
El presente artículo analiza dos procesos recientes en la historia del conflicto armado colombiano -la masacre de Bojayá y la toma por parte de paramilitares a La Sierra (Barrio de la comuna 8 de Medellín)con el fin de mostrar cómo los diversos actores armados implicados configuraron una serie de dinámicas de control poblacional en las dos comunidades. Lo que se sostendrá, es que si bien fueron procesos diferentes, con actores armados diferentes, ambos reflejaron lo que el conflicto en Colombia en sí mismo ha encarnado siempre y que representa un reto para el eventual postconflicto: el que la población, en la confrontación, siempre esté en el medio, literal y discursivamente hablando. Para el caso específico de Bojayá, se tomó como referencia el documental realizado por el Centro Nacional de Memoria Histórica (2010) sobre la masacre allí cometida. En este caso, la reflexión particular de este acontecimiento girará

* $\quad$ El presente artículo responde a una serie de inquietudes planteadas en el curso de pregrado para ciencias sociales de la Universidad Icesi Conflictos y violencia en Colombia. De antemano agradezco a la profesora Valeria Eberle por su apoyo en el proceso de comprensión de esta complicada realidad que nos atañe.

** Estudiante de Sociología y Mercadeo de la Universidad Icesi.
\end{abstract}


en torno a los procesos de memoria de sus víctimas y a cómo esta masacre reflejó una configuración violenta del Estado. Para el caso específico de La Sierra, se tomó como referencia el documental realizado por Scott Dalton y Margarita Martínez Escallón (2003) sobre la cotidianidad de algunos miembros del Bloque Metro de los paramilitares en la comuna 8 de Medellín. En este caso, la reflexión se basará en un análisis del discurso inmerso en el documental, para mostrar la dinámica necropolítica alrededor del control poblacional.

\section{Palabras clave}

Bojayá/La Sierra, Memoria, Configuración violenta del Estado, Necropolítica/Control territorial-poblacional.

\section{Introducción}

El debate por la verdad ha sido un problema en Colombia que ha trastocado las esferas de lo jurídico, lo económico, lo político y lo sociocultural. En medio del conflicto, se han implantado mecanismos legales para poder esclarecer los múltiples hechos violentos que vienen afectando al país desde hace más de cinco décadas. Entonces, como método para saber qué pasó, la ley le ha dado agencia a los victimarios para que en un acto de "sinceridad" le digan al país la verdad y, sobre todo, le digan a las víctimas por qué. En esa dinámica, las victimas aparecen en el imaginario como las afectadas y no como las garantes de un relato que pueda aclarar los hechos desde una perspectiva diferente a la del victimario. Sin embargo, con la masacre de Bojayá la pregunta por la verdad comenzó a privilegiar el relato de la víctima: comenzó a privilegiar, pues, la construcción de memoria desde la perspectiva de los afectados, dando cuenta que son ellos, al estar en la mitad, quienes pueden construirla a partir sus propios problemas.

En ese ejercicio fue y sigue siendo fundamental el papel del Centro Nacional de Memoria Histórica, que en su momento fue el productor de uno de los documentales que serán analizados, "Bojayá: Guerra sin límites" (2010), y que de algún modo se ha planteado la construcción de memoria como un proceso fundamental para la reparación de las víctimas y para la transición hacia el posconflicto. Por todo esto, en primer lugar, interesa analizar el relato de las víctimas de la masacre de Bojayá alrededor de tres aspectos fundamentales: 1) como un relato colectivo que privilegia la construcción de memoria a través de la acción colectiva; 2) como un relato colec- 
tivo que desde la perspectiva de víctimas, ayuda a manifestar la dimensión violenta en la configuración del Estado; y 3) como un relato colectivo que involucra a Bojayá como acontecimiento más allá de su lugar como territorio y que da cuenta del famoso adagio del conflicto armado en Colombia de la población en el medio.

Ahora bien, la pregunta por el conflicto en Colombia se ha ido diversificando. Pensar el conflicto y la violencia en Colombia es pensar en lo rural, pero también en lo urbano; es pensar en las armas, pero también en el uso simbólico del terror; es pensar en la muerte: pero sobre todo, es pensar en la administración de la vida. En ese sentido, La Sierra, documental grabado en 2003 en la comuna 8 de Medellín por Scott Dalton y la periodista colombiana Margarita Martínez Escallón, refleja claramente la expresión última de la soberanía en aras del conflicto: muestra la capacidad de algunos para decidir quién puede vivir y quién debe morir. En suma, el conflicto en Colombia, visto desde La Sierra, muestra un ejercicio de la soberanía que implica, para controlar un territorio, también un control sobre la vida del Otro. Es por esto que, en segundo lugar, se realizará un análisis discursivo del relato no solo de los personajes y las subjetividades que muestra el documental, sino también un análisis discursivo del documental mismo, tratando de mostrar una lectura del conflicto en Colombia. Para tal ejercicio, se utilizará especialmente la propuesta conceptual de Achille Mbembe, y otros autores, sobre la necropolítica, para tratar de reflexionar sobre el conflicto que expone el documental, que es en últimas la pregunta sobre la política como violencia: la política como un trabajo de muerte y que, en este caso, involucra a la población directamente.

\section{Bojayá}

La constitución de los sujetos políticos puede concebirse a partir de una rearticulación de la subjetividad colectiva que opera en la desnaturalización de los sentidos hegemónicos. Esta instancia de la subjetividad colectiva permite un corrimiento, un acto de identificación, la subjetivación y la apertura de instancias relativamente autónomas de conformación surgidas de la ruptura de la sujeción; alli el sujeto parcialmente se autodetermina. Lo político y La política, Martín Retamozo (2009). 


\section{Una breve contextualización}

Ahí, en plena cabecera municipal, hacia las 6 de la tarde y con una incertidumbre más grande que la tragedia que iba a sacudir al pueblo, una gran proporción de los habitantes del municipio de Bojayá, Chocó, apelaron como su última esperanza, ante la amenaza venidera, a esconderse en ese espacio sagrado que en ese momento no sería testigo de una tradicional misa: la iglesia. Cuando las botas "pantaneras" no coincidieron con las de cuero, los habitantes sabían que algo muy malo iba a suceder y creyeron que fuera lo que fuera, "la casa de Dios la iban a respetar". Así que ya adentro, más de un centenar de personas nunca se imaginaron que un cilindro iba a explotar y que como consecuencia el terror al pueblo iba a llegar. El resultado: 79 personas muertas, 115 heridos y un relato colectivo que contar.

A raíz del ataque el 2 de mayo de 2002 del frente Mario Vélez de las FARC-EP con cilindro bomba a los paramilitares que estaban ocupando la cabecera de Bellavista de Bojayá, se repetiría el usual adagio del conflicto en Colombia: la población en la mitad. No importando el lugar simbólico de un espacio como la iglesia, la preocupación del grupo guerrillero era recuperar el control territorial por medio del violento ataque a los paramilitares que, al parecer, tampoco les importó usar a los habitantes como escudo humano para preservar sus filas. Según cuentan los sobrevivientes, horas antes del ataque, algunos pobladores le habían pedido encarecidamente a los paramilitares que se retiraran de la cabecera, recibiendo rotundas negativas que calarían en una crónica de una masacre anunciada, pues al fin y al cabo "Bojayá fue el detonante donde se supo que nos estaban matando en el medio Atrato" en palabras de Delis Palacios .

\section{El relato colectivo, la memoria y la acción colectiva}

Todas estas experiencias sobre lo ocurrido obedecen al relato del niño que ya es grande, de la mujer que ya es más madura, de la anciana que ya no está, de la diócesis de Quibdó, en una palabra, obedecen a un relato colectivo que privilegia la construcción de memoria sobre lo que sucedió. El relato que tenemos de Bojayá es el relato de sus víctimas, de sus dolores, de su tristeza, de su temor, de su desconfianza. Este relato refleja, como diría Romero, cómo "la violencia se volvió parte de la rutina política como resultado de la competencia de los actores armados en diferentes regiones", en 
este caso entre guerrilleros y paramilitares inscritos en una guerra sucia por el control sobre el territorio (Romero, 2005: 20). Cada testimonio, pues, se rehúsa a olvidar y, en su discurso, exigen la verdad.

¿Habrá sido esta masacre el resultado de una combinación de acciones planificadas y racionales por parte de los grupos implicados? ¿Habrá sido ésta- siguiendo la mirada de González, Bolívar y Vázquez- una acción colectiva consensuada? Para estos autores, en una propuesta bastante interesante, "los paramilitares y las FARC obedecen a dos casos de acción colectiva violenta orientadas políticamente, que se insertan en estructuras espaciales que generan condiciones de violencia" (Bolívar et al, 2009: 44). Sin embargo, sería bastante apresurado hacer afirmaciones en situaciones tan delicadas como estas, y más cuando se sostiene que el Estado también estuvo implicado de modo indirecto en dicha masacre: en pocas palabras, cuando todavía esa verdad es bastante insipiente.

De todos modos, un aspecto relevante de ese relato colectivo de los testimonios del documental, a propósito de la propuesta de dichos autores, es la forma como privilegia la construcción de memoria, pero fundamentalmente a través de la acción colectiva. Todos los relatos, sin excepción, son construcciones simbólicas realizadas alrededor de asociaciones, agremiaciones o grupos de misioneros. A diferencia de lo que ocurrió con los relatos sobre la Violencia en donde lo que se pudo saber de dicho periodo fue gracias a experiencias concretas, individuales e intersubjetivas como en el caso de "Los años del tropel" (Molano, 2006), en Bojayá es clave cómo la memoria se ha ido construyendo gracias a un relato común de sus víctimas, lo que las convierte en actores fundamentales del conflicto en Colombia.

Entonces aparece Delis no como víctima sino como la principal dirigente de la Asociación de Víctimas Dos de Mayo (ADOM); aparece la hermana Agustina como la voz de las misioneras; aparece el líder Embera como el representante de la ASOREWA; Leyner Palacios como el líder de COCOMACIA; el sacerdote Jesús de las Diócesis de Quibdó; y así muchas otras asociaciones que se fueron creando como forma de agenciar colectivamente lo sucedido. En síntesis, lo neurálgico a resaltar es que la construcción de ese relato, del que se ha venido hablando, fue el resultado de la acción colectiva de los habitantes de Bojayá que se agruparon y movilizaron alrededor 
de diversas asociaciones con el fin exclusivo de enriquecer el debate por la construcción de memoria y el reclamo ante el Estado por sus derechos: es decir, como actores fundamentales en el conflicto por el simple hecho de estar siempre en el medio.

\section{El relato colectivo y la configuración violenta del Estado}

Cada testimonio insta en responsabilizar a la guerrilla por su crimen de guerra, a los paramilitares por usar a la población civil como escudo y, sobre todo, al Estado por su omisión por no repeler a los segundos cuando salieron libremente desde Turbo hacia Bojayá. Las pancartas, las movilizaciones, las arengas, todas coinciden en responsabilizar, además de los grupos implicados, al Estado colombiano no solo por no proteger la vida de las victimas durante la masacre sino también por no cumplir con los procesos de reparación, restablecimiento, garantías de no repetición y verdad. Lo importante a destacar como segundo aspecto de ese relato colectivo, es cómo desde la perspectiva de los afectados, como actores del conflicto, se manifiesta el proceso de configuración violenta del Estado.

La exigencia y los reclamos por parte de los habitantes de Bojayá constituyen un aspecto relevante: no son bojayaseños quienes exigen; son víctimas de la masacre de Bojayá quienes a través de la acción colectiva hacen valer sus derechos. En el momento en que el Estado reconoce que debe cumplir con los procesos de reparación, restablecimiento, garantías de no repetición y verdad para los afectados de Bojayá, está reconociendo y legitimando el lugar simbólico de la categoría socio-jurídica de las víctimas como unos actores dentro del conflicto. Cuando esto ocurre, las víctimas se convierten en sujetos políticos que construyen una subjetividad colectiva como formas de autoidentificación en su lugar en medio del conflicto. Como se expuso más arriba, citando a Retamozo:

La constitución de los sujetos políticos puede concebirse a partir de una rearticulación de la subjetividad colectiva que opera en la desnaturalización de los sentidos hegemónicos [...] permite un corrimiento, un acto de identificación, la subjetivación y la apertura de instancias relativamente autónomas de conformación surgidas de la ruptura de la sujeción; alli el sujeto parcialmente se autodetermina (Retamozo, 2009: 86). 
En este sentido, entender la configuración moderna de un Estado como el colombiano, es entender el lugar que se le da a los ciudadanos clasificados simbólicamente en categorías sociojurídicas como "desplazados", "victimas", "victimarios", "comunidades", "terroristas", "desmovilizados": es decir, es entender que a cada sujeto se lo convierte en un sujeto político implicado necesariamente en categorías que sirvan como dispositivos de control, ya sea para llevar estadísticas, ya sea para intervenir o ya sea para no hacer nada. Entender la configuración del Estado es observar cómo estas categorías se convierten en cifras y cómo esas cifras sirven para legitimar la gobernabilidad: es entender el ejercicio de gobernar como la estrategia biopolítica de ejercer "un micropoder sobre el cuerpo que también dé lugar a medidas masivas, a estimaciones estadísticas, a intervenciones que apunten al cuerpo social entero o a grupos tomados en conjunto" (Foucault, 2002: 176). Entender la configuración del Estado colombiano es observar cómo la diversidad se delimita al autoreconocimiento muchas veces impuesto precisamente desde esa construcción de categorías, pues "el drama del reconocimiento se representa en el plano individual, pero también entre grupos" (Taylor, 1996: 18). Entender la configuración del Estado, pues, es escuchar a Delis cuando dice que se autoreconoce como afro, como víctima y como representante de una asociación de víctimas.

De todos modos, es significativo destacar el carácter violento de esa configuración, pues el Estado a la vez que reconoce que debe cumplir con los procesos de reparación, restablecimiento, garantías de no repetición y verdad, coacciona ese derecho cuando no privilegia la voz de las víctimas sino la de los victimarios y cuando se dedica a "construir obras de infraestructura solo después de las tragedias, sin reconstruir el tejido social de la comunidad" en palabras de Delis. Según Benjamin, en esta "diferencia de interpretación se expresa la contradicción práctica de la situación jurídica, según la cual el Estado reconoce un derecho, frente a cuyos fines, en cuanto naturales, se mantiene indiferente, pero en caso extremo se les opone de manera hostil”. (Benjamin, 2001: 5).

En ese orden de ideas, la violencia política en ese proceso de configuración "sería un medio instrumental para conseguir ciertos fines específicos (gobernabilidad por ejemplo) y, por lo tanto, requiere de una justificación externa" que en este contexto sería la ley como forma legítima de acción (Retamozo, 2009: 87). 


\section{El relato colectivo, el acontecimiento y la población en el medio}

Además de resaltar el lugar de la acción colectiva y la configuración violenta del Estado en el relato colectivo de las víctimas, se debe analizar brevemente cómo dicho discurso involucra a Bojayá como acontecimiento más allá de su lugar como territorio y cómo dicho evento permite reflexionar sobre el lugar de la población. En términos sociológicos, tomando la concepción de Fernand Braudel, el acontecimiento se podría definir como un hecho histórico, que impacta fuertemente en las representaciones de los sujetos y que da lugar a una serie importante de cambios en diversas esferas de la estructura social. Braudel, al definir este concepto, criticaba la versión tradicional de la historia que se conformaba sólo con la descripción básica del acontecimiento y no analizaba el contexto en el que efectivamente se presentaba. Para este autor, los acontecimientos deben ser ubicados temporalmente y deben ser analizados con los lentes del pasado y no con los lentes del ahora (Braudel, 2002).

Bojayá, pues, comenzó a hacer parte de las representaciones de los medios de comunicación, de la opinión pública, de una proporción de colombianos no como un municipio turístico del Chocó rico en fauna silvestre y diverso en culturas; Bojayá es la "masacre de Bojayá", son los 79 muertos, los 115 heridos, la iglesia destruida, la virgen sin manos, en una palabra, Bojayá es el relato colectivo de sus víctimas. Como ya se había sostenido, lo que se ha podido saber de la masacre obedece a las experiencias colectivas de los habitantes que presenciaron el ataque y lograron sobrevivir: pues gracias a iniciativas como el documental realizado por el Centro de Memoria Histórica, se ha privilegiado la voz de las víctimas y no la de los victimarios con los lentes puestos siempre en la experiencia ad hoc.

Esta forma de conocer lo sucedido, el que las víctimas se hubieran organizado en asociaciones para exigir sus derechos, la difusión en medios, el que Bojayá apareciera en la mente no solo de los bojayaseños sino de muchos otros colombianos de esa forma particular gracias, por primera vez, al relato de las víctimas, convierte este hecho histórico en acontecimiento. Bojayá es un acontecimiento en tanto que transformó la forma en que estábamos leyendo el conflicto al darle agencia y al haber privilegiado el relato de los que siempre están en medio: sus víctimas.

Lo que particularmente también hace que Bojayá y el Salado, por ejemplo, estén en el imaginario de las personas de esa forma específica, es el número de víctimas: pues en un país donde el conflicto es algo tan cotidiano y donde no sorprende escuchar en los 
medios todos los días que hubo cierta cantidad de muertos, cuando esa cifra se vuelve escandalosa como en los casos mencionados, el hecho cotidiano se vuelve histórico.

Esta cuestión vincula directamente al acontecimiento con la difusión mediática y con la construcción simbólica de discurso que hacen los mismos medios para "informar", $¿$ o acaso lo ocurrido en el Chengue o Macayepo, por ejemplo, no fue lo suficientemente traumático? Las víctimas están reclamando el lugar que les pertenece como actores del conflicto armado. Las victimas están alzando su voz de protesta ante un Estado que privilegia la verdad por parte de los victimarios y no la verdad contada por ellas mismas. Las víctimas, pues, han tenido la difícil tarea de auto-visibilizarse por medios alternativos como el relato colectivo ante la indiferencia de muchos por reconocer que la más perjudicada con esta guerra es precisamente la población: la que está y estará siempre en la mitad.

\section{La Sierra}

El número definitivo de muertos había pasado a treinta y cuatro. No se sabe de dónde ni cómo nació la idea, en seguida aceptada por todo el mundo, de que los cuerpos no deberían ser enterrados en los cementerios como muertos normales, que las sepulturas deberían quedarse per omnia saecula saeculorum en el terreno ajardinado fronterizo a la estación del metro. Ensayo sobre la lucidez, José Saramago (2004).

\section{Una breve contextualización}

Cuando se habla de Colombia como un país diverso en su gente, en su fauna y en sus prácticas culturales, se nos olvida muchas veces que Colombia también es un país diverso en cuanto a sus actores armados. No bastándonos con los famosos bandoleros de los años de la Violencia, fueron surgiendo grupos de guerrillas liberales que calaron en lo que hoy se conoce como las FARC (Pizarro, 2011). Fueron surgiendo, también, guerrillas foquistas que hoy el país reconoce como el ELN (Peñate, 1999) y fueron surgiendo las hoy extintas EPL y M-19, ésta última, una guerrilla fundamentalmente mediática y con fuertes vínculos en las ciudades (Bateman tomado en Lara, 1995): estrategia militar a la que apelaría igualmente el ELN, sobre todo en la zona de ladera de Medellín. Ya con cuatro grupos 
guerrilleros grandes, los ochentas demostraron al país y al mundo entero que el conflicto por el control territorial crearía focos de violencia de diversos grupos, además de los mencionados grupos de izquierda: y con el narcotráfico, el paramilitarismo.

Como muy bien lo señala Gustavo Duncan en su texto "Los señores de la guerra: de paramilitares, mafiosos y autodefensas",

\begin{abstract}
"los paramilitares, como grupo armado, estaban marcados por su carácter de subordinación a otros actores del conflicto (...) eran estructuras de guerra construidas en paralelo a otras estructuras con intereses superiores a los suyos" esto es, los terratenientes, en un primer momento, y los narcotraficantes, en un segundo momento (Duncan, 2007: 242).
\end{abstract}

Como lo expresa Duncan, el mito fundador establece que los paramilitares comenzaron a surgir ante la necesidad de los terratenientes de evitar el boleteo de las guerrillas: comenzaron a surgir con un discurso fundamentalmente anti-insurgente. Sin embargo, en otras zonas y en años posteriores, sus funciones se diversificaron hacia la protección de los bienes ilícitos de los narcotraficantes: se comenzaron a conformar como ejércitos privados al servicio del narcotráfico.

De todos modos, el proyecto paramilitar, con el liderazgo de los hermanos Castaño, estableció la ardua necesidad de unir a todos los focos paramilitares de Puerto Boyacá, Barrancabermeja, sur de Bolívar, Antioquia y Córdoba con la pretensión de establecer fuertes vínculos y redes locales de poder y así marcar una cierta independencia frente a los narcotraficantes en el financiamiento de sus filas. En palabras de Duncan, "el proyecto de las autodefensas pretendía imprimir un tipo de organización política al interior de los territorios protegidos, de modo tal que no se limitara su accionar al simple hecho de ser escoltas de narcos" (Duncan, 2007: 249). En síntesis, fue el clientelismo armado la principal herramienta de los paramilitares para seguir ejerciendo soberanía sobre los territorios que antes protegían para los narcos. Fue en esa dinámica, precisamente, que las redes del poder local de los paramilitares se extendieron hasta las ciudades con el fin de debilitar la esfera política de las FARC- ante su confrontación por el poder local- a través del masivo asesinato de miembros de la Unión Patriótica: además, no debían dejar que se siguiera extendiendo el poder de las milicias urbanas del M-19 y el ELN. 
El poder de los paramilitares, en ese sentido, llegó a finales de los ochenta y principios de los noventa a las ciudades, particularmente a Medellín, reforzándose en 1996 con la creación del Bloque Cacique Nutibara en el nororiente antioqueño (Reyes, 1997). Pero no llegó a cualquier Ciudad. El poder llegó a la ciudad excluida por la gran ciudad: el poder llegó a la ciudad que veía desde arriba como estaba siendo excluida por la de abajo. Ya ahí, en la ladera, en la montaña, en la Sierra donde Cielo y el cielo se encuentran para "ir a Medellín a visitar al novio que está en la cárcel", las voces que claman la paz se encuentran con las balas que nunca dejaron de sonar. Y hablaron Edison y Jesús, dos jóvenes a los que la guerra tomó y nunca soltó.

\section{El control sobre el territorio como un ejercicio político de muerte}

El caso de La Sierra, como también el de Bojayá, sin duda alguna reflejan la expresión última de la soberanía en aras del conflicto: muestra la capacidad de algunos para decidir quién puede vivir y quién debe morir. Algunos como Edison y Jesús, quienes a sus escasos 22 y 19 años de edad respectivamente tenían sobre sus espaldas no sólo el pasado y oxidado fúsil de la guerra sino también la difícil responsabilidad de proteger a la comunidad: de proteger el territorio, su territorio. Sus vidas, contando a Cielo, tenían mucho en común: dejaron de estudiar, fueron padres muy jóvenes y, lo más importante, como pobladores nacieron en medio de la guerra, en medio de las balas. No todos aprendieron a disparar a la misma edad, pero todos crecieron viendo cómo cada día amanecía con los pájaros cantar y un olor nauseabundo de los cuerpos tirados a las orillas del chaflán.

La Sierra refleja la escabrosa cotidianidad del Bloque Metro de los paramilitares en la comuna 8 de Medellín en 2003, alrededor de la vida de dos de sus más importantes integrantes, Edison (el jefe) y Jesús (uno de sus integrantes) y alrededor de la vida de Cielo, esposa de un asesinado integrante del mismo grupo, novia durante el documental de otro e icónica figura de una subjetividad construida en medio de las balas. Por tal motivo, es especialmente llamativo el lugar simbólico que tiene la construcción de la masculinidad y la feminidad en los individuos de la población en tiempos de conflicto. "Las mujeres acá son desesperadas por el sexo" decía tímido ante la cámara Edison, padre de 8 hijos con distintas mujeres: "les gustan ver a los hombres con armas, les gusta el peligro". 
Por otro lado, Jazmín, una de sus mujeres, hablaba de lo triste que había sido que su papá le dedicara más tiempo a las armas y a la guerra que a ella, sin percatarse que su esposo era el vivo reflejo de eso que tanto odiaba: pero también de eso que tanto amaba. Cielo, igualmente, ante la muerte de su esposo Carlos, miembro del Bloque Metro, siguió apelando a ese modelo de masculinidad: a ese modelo que refleja poder y peligro a la vez. Más allá de una lectura psicoanalítica al respecto, un primer punto fundamental para comprender otro asunto del conflicto en Colombia y su relación con la construcción de sujetos sexuados, es cómo la construcción de la masculinidad y la feminidad es sin lugar a dudas una construcción discursiva: cómo el arma constituye el falo cargado simbólicamente de poder (Sampson, 2000) y cómo el tener muchos hijos se constituye como una demostración de una masculinidad que encuentra allí, la forma de reproducir ese poder. Porque por más que Edison haya querido tener solo hijas, sabe que sus hijos harán honor a su nombre. Como diría Cielo refiriéndose a su hijo: "el niño dice que va a matar a los que mataron a su papá". En últimas, en el arma el hombre deposita su libido, la mujer encuentra su objeto de deseo y las balas, al mismo tiempo, atraviesan al enemigo.

En ese sentido, para comprender este prolongado conflicto, en el caso de La Sierra, es fundamental tener en cuenta el lugar de la excepcionalidad: el lugar de la soberanía. El que Edison y Jesús durante el día fueran unos, haciendo parte de la población, estando "tranquilos", visitando a sus familias, vistiendo pantalonetas y camisetas deportivas, y en la noche otros, vistiendo pasamontañas, pantalones camuflados con un radio y un arma como los mejores aliados, demuestra una manifestación de poder en donde se ejerce control sobre absolutamente todo. La meta fundamental de este conflicto es el control del territorio y la población, por lo que se hace todo lo que sea necesario para extender ese control por medio de la guerra hasta las últimas consecuencias.

Según Mbembe, "la guerra también es un medio para establecer la soberanía, tanto como un modo de ejercer el derecho a dar la muerte" (Mbembe, 2011: 20). En el caso de La Sierra, la guerra por el territorio aparece no solo como el ejercicio sistemático de matar al Otro enemigo, sino también como el ejercicio sistemático de decidir quién vive y quién muere: en suma, la guerra en el contexto de La Sierra es un ejercicio necropolítico por excelencia. El análisis que aquí se propone particularmente, es que en la dinámica del 
ejercicio de soberanía, estos jefes paramilitares no sólo tuvieron agencia sobre la vida del eventual Otro enemigo ELN, sino también sobre la vida de la población, que estaba en medio; y, paradójicamente, sobre su propia vida teniendo en cuenta que también hacían parte de la población de un modo particular que ya se explicará.

Hay que recordar que el modelo de paramilitarismo tipo Bloque Metro, al que pertenecían Edison y Jesús, obedeció tal vez a los últimos brochazos del proyecto de las autodefensas como organización denominada de esa forma. En palabras de Duncan, se podría llamar a esta etapa "la degradación desde sus adentros del proyecto paramilitar", pues "la infiltración del narcotráfico dentro del proyecto paramilitar degradó la identidad inicial de las autodefensas (...) en respuesta a la guerrilla" (Duncan, 2007: 266). El que Edison y Jesús dispararan contra las milicias del ELN de un lado a otro no obedeció de necesariamente a una guerra por la ideología ni a un proyecto esencialmente anti-insurgente: obedeció, como se ha venido sosteniendo, a una guerra física y simbólica por el territorio y el control poblacional.

Allí donde hay tierra que habitar y proteger y poblaciones que controlar, las balas ocupan un lugar más importante que la ideología: o, más bien, la ideología se limita al ejercicio sistemático de matar. En ningún momento estos dos personajes se refirieron de forma crítica al ELN como el enemigo a eliminar. En esta guerra el lugar del enemigo se desdibuja, no se sabe quién realmente lo es, pues como diría Edison "yo no me siento tranquilo porque todos quieren el poder". Bajo esa lógica del enemigo interno cualquiera lo puede ser: el ELN, la comunidad y hasta ellos mismos.

Por esta razón, la dinámica de la excepcionalidad en el ejercicio de la necropolítica, desde esta lectura, por lo observado en el documental, no se limitó a la administración del derecho de dejar vivir o hacer morir a ese eventual enemigo interno construido como el ELN; el estado de excepción en esta guerra fue y es para todos, inclusive para esa población que decían querer proteger a pesar de que en las mañanas siguientes a los constantes tiroteos aparecieran personas muertas de la comunidad: ancianos, mujeres, tal vez niños. La población al estar en medio- pensando la premisa de forma metafórica y discursiva y en este caso también literal- sufre las peores consecuencias de esta guerra. El campo de batalla del conflicto en Colombia está conformado, sobre todo, por la sangre y las lágrimas de las víctimas que están en el medio: 
como lo ocurrido en Bojayá relatado más arriba. Sobre este punto, Giorgio Agamben, pensando en la lógica campo de concentración traslapable a lógica de excepcionalidad misma, nos dice:

\begin{abstract}
"Si la esencia del campo consiste en la materialización del estado de excepción $y$ de la consiguiente creación de un espacio para la vida desnuda como tal, deberemos admitir, entonces, que nos encontramos virtualmente en presencia de un campo cada vez que una estructura así se crea, independientemente de la entidad de los crimenes que alli se cometan, y cualesquiera sean su denominación y su topografia específica" (Agamben, 2001: 37).
\end{abstract}

La Sierra se constituyó en su momento, entonces, como un estado de excepción en sí mismo. Toda suerte de ley, norma, imaginario o representación se suspendió. Los señores de la guerra- en este caso jóvenes de la guerra Edison y Jesús, como buenos soberanos en el ejercicio de la necropolítica por el control territorial y poblacionaldecidían qué se debía hacer y cómo se debía hacer, pues al fin y al cabo ellos eran la autoridad. Según Edison, "este barrio es la vida de nosotros (...) mientras estemos, vivos de aquí no nos dejamos sacar", lo que implicó que el estado de excepción afectara las esferas más íntimas de lo social. El estado de excepción afectó el uso y lugar del lenguaje, el lenguaje de la guerra: "lo pelaron en la esquina", "me encantan los fierros", "cuando sea grande quiero ser guerrero", "los hombres somos más fuertes que las mujeres", "me da miedo lo que pase con mi familia, no conmigo".

El relato alrededor de la masacre de Bojayá y la toma en La Sierra es el relato de la guerra. La cotidianidad misma de la gente estuvo atravesada siempre por la guerra: ver al muerto lleno de moscas a la orilla de la acequia se hacía normal tanto para el niño como para el anciano que veía otro igual a él tirado en el piso. Como diría Mbembe, "el terror se erige como componente necesario para el ejercicio necropolítico" (Mbembe, 2011: 27).

El ejercicio necropolítico de control territorial en ambos casos implicó una dinámica de relacionamiento de los paramilitares o guerrilleros, como los soberanos, con las personas que habitaban dichos territorios desde diversas formas de representación simbólica: un relacionamiento a través, precisamente, del lenguaje, de los muertos 
visiblemente ensangrentados, de los espacios de socialización, en una palabra, de la cotidianidad. Ese relacionamiento en medio del estado de excepción se llegó a justificar inclusive por medio del alcance "por fin" de la paz, por más eso implicara también la muerte de esos que tanto la anhelaban: las personas de la comunidad. Así, pues, "el estado de excepción es necesariamente violento, aunque solo sea en aras de la preservación de la paz" (Sampson, 2000: 14). Como diría un habitante de La Sierra al inicio del documental: "la vida de nadie vale nada", sobre todo, en el ejercicio de la necropoder como dispositivo para el control territorial y poblacional.

\section{Reflexiones finales}

El presente artículo analizó la masacre de Bojayá y la toma por parte de paramilitares a La Sierra (Barrio de la comuna 8 de Medellín) con el fin de mostrar cómo los diversos actores armados implicados configuraron una serie de dinámicas de control poblacional en las dos comunidades. Para el caso de Bojayá, se analizó el relato de las víctimas de la masacre de alrededor de tres aspectos fundamentales: como un relato colectivo que privilegia la construcción de memoria a través de la acción colectiva; como un relato colectivo que desde la perspectiva de víctimas, ayuda a manifestar la dimensión violenta en la configuración del Estado; y como un relato colectivo que involucra a Bojayá como acontecimiento más allá de su lugar como territorio.

Para tal reflexión fue fundamental hacer una lectura del documental como un homenaje a la memoria de Bojayá a partir de una serie de relatos construidos colectivamente; fue fundamental apreciar la noción de víctimas como una categoría que convierte a los afectados en actores del conflicto como sujetos políticos; y fue fundamental, también, tratar de definir qué implicó Bojayá como acontecimiento en donde se visibilizó una cruda realidad del conflicto armado colombiano: la población siempre en la mitad. Como habrá podido observar el lector, el análisis de este proceso se basó sustancialmente en la experiencia subjetiva de Delis Palacios (víctima en Bojayá). Desde el primer momento en que ella intervino, en sus palabras, en sus gestos y en su tono de voz, se percibió la importancia que tiene la construcción de memoria para el ejercicio de reparación, restablecimiento y garantías de no repetición para estas poblaciones. 
Para el caso de La Sierra, el documental refleja claramente la expresión última de la soberanía en aras del conflicto: muestra la capacidad de algunos para decidir quién puede vivir y quién debe morir. En suma, La Sierra refleja el ejercicio de la necropolítica como dispositivo poderoso y eficiente para ejercer control sobre un territorio y la población. La intención en esta parte del artículo era hacer una lectura del conflicto reflejado en el documental en aras de las implicaciones que tuvo ese necropoder no sólo sobre el eventual enemigo (ELN), sino también sobre la población y sobre la misma subjetividad de los soberanos en cuestión, Edison y Jesús, ante el desdibujamiento en medio de la guerra de la figura de la amenaza: pues ante la disputa del territorio, cualquiera lo puede ser, inclusive los mismos paramilitares como fue el caso del Bloque Cacique Nutibara, bajo la lógica del enemigo interno.

En ese sentido, se reflexionó alrededor de la forma como se construyeron los sujetos sexuados en medio de la guerra, cómo se construía la masculinidad y la feminidad en los pobladores, cómo la guerra se convierte en últimas en la única forma que tienen sus guerreros de liberar esa energía libidinal y cómo las armas y el peligro se convierten en un objeto de deseo fundamental para las mujeres en medio de las balas. Así mismo, se cuestionó el lugar de la ideología cuando hay de por medio un ejercicio sistemático de necropolítica con relación a la construcción de ese eventual Otro-enemigo que decían estos jóvenes, fue por un momento el ELN. Ya en la parte final- planteando a La Sierra como un estado de excepción en sí mismo dadas las condiciones de suspensión de la ley- se analizó la implicación que tenía el ejercicio soberano de Edison sobre el territorio, respecto a la importancia del relacionamiento con la comunidad; relacionamiento que implicó una transformación de aspectos como el lenguaje, los espacios de socialización y, en general, la cotidianidad misma en la comunidad: proceso de adaptación al estado de excepción ante el inminente riesgo de morir.

Respecto a los dos procesos analizados conjuntamente, se puede decir que tanto el relato de la masacre de Bojayá como el de la toma a La Sierra, constituyen los relatos de la guerra. La cotidianidad de ambas comunidades, estuvieron atravesadas por la guerra. El ejercicio necropolítico de control territorial y poblacional en ambos casos implicó una dinámica de relacionamiento de los paramilitares o guerrilleros, como los soberanos, con las personas que habitaban dichos territorios desde diversas formas de 
representación simbólica: un relacionamiento a través, precisamente, del lenguaje, del terror, de las balas, en pocas palabras, de la cotidianidad. Ese relacionamiento en medio del estado de excepción se llegó a justificar inclusive por medio del alcance "por fin" de la paz, por más eso implicara también la muerte de esos que tanto la anhelaban: las personas de la comunidad.

Ya como reflexión final y para dejar el debate abierto, sería interesante analizar el lugar simbólico en general que ocupó el cuerpo del soberano como instrumento dosificado en medio de esta guerra, apelando a las escenas finales de La Sierra: en este caso, del entierro de Edison. En medio de una comunidad que lo lloraba, en medio de sus más de cuatro mujeres que lo aclamaban, fue interesante observar cómo el soberano lo seguía siendo a pesar de ya no estar, a pesar de estar muerto. Fue interesante, pues, observar cómo la gente rogaba por su alma a pesar de ser víctimas de ese ejercicio de excepcionalidad por parte del dispositivo necropolítico de ese soberano que estaba muerto: porque en sus corazones, él seguía vivo para proteger a La Sierra. Edison pasó de joven de la guerra a mártir de la guerra al que le suelen rezar todos los 24 de cada mes.

Así, pues, para entender el conflicto en Colombia también hay que entender el lugar que ocupa el cuerpo del mártir, del líder, del jefe como elemento visiblemente simbólico del proyecto necropolítico en medio de un estado de excepción, tanto para quienes los lloran como para quienes se regocijan de tenerlo como trofeo: como ha ocurrido ya con la exposición de los cuerpos de los guerrilleros Raúl Reyes y Alfonso Cano por parte del gobierno colombiano. El cuerpo, pues, se vuelve esencial. Para el seguidor del mártir es necesario volver a la lucha cuerpo a cuerpo con el enemigo como forma de vendetta, como se planteaba en las guerras de antes, pues "cada enemigo masacrado aumenta el sentimiento de seguridad del superviviente" (Mbembe, 2011: 66). Así mismo "el candidato a mártir transforma su cuerpo en máscara (...) el cuerpo no sólo esconde el arma: el cuerpo se transforma en el arma, y no en un sentido metafórico sino literal, balístico" (Mbembe, 2011: 67). Lo que le importa al mártir es acabar con el cuerpo del "Otro" al tiempo que acaba con el suyo, ¿o acaso Edison y Jesús o los guerrilleros y paramilitares de Bojayá pensaban en el futuro? 


\section{Bibliografía}

AGAMBEN, Giorgio (2010). Homo sacer I: El poder soberano y la nuda vida. Valencia, España: Pre-Textos.

AGAMBEN, Giorgio (2010). Homo sacer II: El estado de excepción. Valencia, España: Pre-Textos.

AGAMBEN, Giorgio (2001). ¿Qué es un campo? En: A. Cuspinera (Comp.), Medios sin fin. Notas sobre la politica (pp. 37 - 43). Valencia, España: Pre-textos.

BENJAMIN, Walter (2001). Para una crítica de la violencia. En: E. Subirats (Comp.), Iluminaciones $I V$ (pp. 23 - 45). Madrid, España: Taurus.

BRAUDEL, Fernand (2002). Las ambiciones de la Historia. Barcelona, España: Crítica.

DUGAS, John (1993). El desarrollo de la Asamblea Nacional Constituyente. En: J. Dugas (Comp.), La Constitución de 1991: ¿un pacto político viable? (45 - 76). Bogotá, Colombia: Universidad de los Andes.

DUNCAN, Gustavo (2007). Los señores de la guerra. De paramilitares, mafiosos y autodefensas en Colombia. Bogotá, Colombia: Editorial Planeta.

ESPOSITO, Roberto (2008). Comunidad, inmunidad y biopolítica. Barcelona: Herder.

FOUCAULT, Michel (2002). Historia de la sexualidad. I- La voluntad de saber. Buenos Aires, Argentina: FCE.

GONZÁLEZ, Fernán; BOLÍVAR, Ingrid; VÁSQUEZ, Teófilo (2009). Violencia política en Colombia: de la nación fragmentada a la constitución del Estado. Bogotá, Colombia: CINEP.

LARA, Patricia (1995). Siembra vientos y recogerás tempestades. Bogotá, Colombia: Editorial Planeta.

MBEMBE, Achille (2011). Necropolítica seguido de Sobre el gobierno privado indirecto. Numancia, España: Editorial Melusina.

MOLANO, Alfredo (2006). Los años del tropel. Crónicas de la Violencia. Bogotá, Colombia: Punto lectura.

PEÑATE, Andrés (1999). El Sendero estratégico del ELN: del Idealismo Guevarista al clientelismo armado. En: M. Victoria Uribe y D. Malcom (Comp.), Reconocer la Guerra para Construir la Paz (pp. 53-98). Bogotá, Colombia: Universidad de los Andes. 
PIZARRO, Eduardo (2011). Las FARC (1949-2011): de la autodefensa a la combinación de todas las formas de lucha. Bogotá, Colombia: Norma.

RETAMOZO, Martín (2009). Lo político y la política: los sujetos políticos, conformación y disputa por el orden social. En: Revista Mexicana de Ciencias Políticas y Sociales, 1, (206), 69-91.

REYES, Alejandro (1997). Drogas ilícitas en Colombia. Su impacto económico, político y social. Bogotá, Colombia: Ariel.

ROMERO, Mauricio (2005). Paramilitarismo y autodefensas: 1982-2003. Bogotá, Colombia: Editorial Planeta.

SAMPSON, Anthony (2000). Reflexiones sobre la violencia, la guerra y la paz. En: A. Papacchini et al (Comp.), Violencia, guerra y paz. Una mirada desde las Ciencias Humanas (pp. 71 - 99). Cali, Colombia: Universidad del Valle.

SARAMAGO, José (2004). Ensayo sobre la lucidez. Madrid, España: Alfaguara.

TAYLOR, Charles (1995). Identidad y reconocimiento. En: Revista Internacional de Filosofía Política, 1 (7), 1-19.

Videografia

CENTRO NACIONAL DE MEMORIA HISTÓRICA. (Productor). (2010). Bojayá la Guerra sin Límites. [Documental].

DALTON, Scott y MARTíNEZ, Margarita. (Directores). (2003). La Sierra. [Documental]. 